\title{
Digitalisasi Data Muntok White Pepper Untuk Mendukung Produktivitas Dan Pemasaran Secara Global Berbasis Internet Dan Android
}

\author{
Ghiri Basuki Putra ${ }^{1,}$ Eddy Jajang Jaya Atmaja ${ }^{2}$, \\ ${ }^{1}$ Jurusan Teknik Elektro, UBB, \\ ${ }^{2}$ Jurusan Agribisnis, UBB \\ Koresponden email:ghiri-basuki@ubb.ac.id
}

Diterima : 26 Desember 2018

Disetujui : 22 Jnuari 2019

\begin{abstract}
Abstrak
Muntok White Pepper merupakan produk lada Bangka yang sudah terkenal dari sejak dulu dengan kualitas lada yang diakui paling baik diantara lada yang lainnya. Muntok White pepper masih menjadi unggulan hasil pertanian di Bangka Belitung serta merupakan komoditi unggulan yang sudah terkenal di seluruh dunia. Dalam Penelitian ini, penekanan yang hendak diambil adalah pemanfaatan Internet dan aplikasi android sebagai sarana pengelolaan data tentang Muntok White Pepper mulai dari lahan, informasi bibit, produksi, perawatan serta harga dan ekspor Muntok White Pepper. Potensi pengelolaan secara digitalisasi data Muntok White Pepper lebih baik dengan pengelolaan terpusat serta informasi Muntok White Pepper yang lengkap untuk memudahkan mendapatkan produktivitas, luas lahan dan ekspor lada secara lengkap. Dengan menggunakan website yang dapat diakses secara daring dan Aplikasi android untuk membuat akses yang luas dan sistem pengelolaan data Muntok White Pepper dapat berbasis web secara lengkap dan update yang bias menjadi ru-jukan dalam mencari informasi tentang Muntok White Pepper bagi Bangka Belitung maupun orang luar.
\end{abstract}

Kata Kunci: Muntok White Pepper; Digitalisasi; PhP; MySQL; Android

\begin{abstract}
Muntok White Pepper is a well-known Bangka pepper product from a long time ago with the quality of pepper which is best recognized among the other pepper. Muntok White pepper is still a leading agricultural product in Bangka Belitung and is a leading commodity that is well-known throughout the world. This research, the emphasis to be taken is the use of the Internet and android applications as a means of managing data about Muntok White Pepper starting from the land, information on seeds, production, maintenance and prices and exports of Muntok White Pepper. The potential for digitiz-ing management of Muntok White Pepper data is better with centralized management and complete information on Muntok White Pepper to facilitate obtaining productivity, land area and export of pepper in full. By using a website that can be accessed via the Internet and an Android application to make extensive access and a Muntok White Pepper data management system, it can be web-based in full and updated which can be a reference in finding information about pepper.
\end{abstract}

Keywords: Muntok White Pepper, Digitization, PhP, MySQL, Android

\section{Pendahuluan}

Lada merupakan salah satu tanaman rempah rempah yang dikenal sebagai King of Spice merupakan tanaman rempah yang paling penting dalam perdagangan internasional, dan menduduki lebih kurang sepertiga dari total volume dan nilai perdagangan rempah secara global (IPC, 2014: 1). Lada yang diperdagangkan (ekspor dan impor) umumnya berupa lada putih (white pepper), lada hitam (black pepper), ground pepper, green pepper, dan oleoresin. Akan tetapi, dua jenis komoditi lada yang utama atau paling besar keterlibatannya dalam perdagangan lada di dunia adalah lada putih dan lada hitam.

Bangka Belitung merupakan salah satu wilayah yang menghasilkan lada terutama lada putih. Lada putih dari Bangka Belitung sangat terkenal di seluruh dunia dengan merek Muntok White Pepper (MWP). Lada putih Bangka dikenal memiliki kualitas tinggi

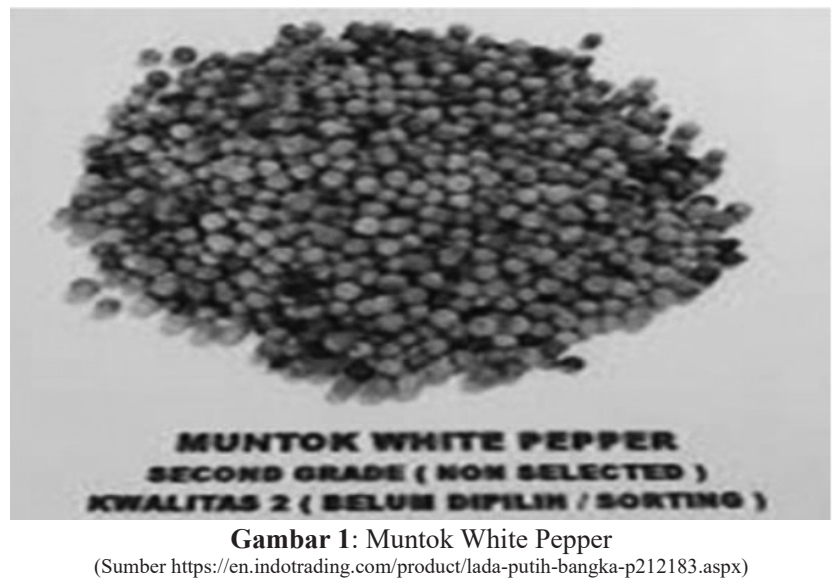

dan harga yang mahal dibandingkan dengan lada hitam. Permasalahan untuk lada Bangka Belitung ini adalah belum adanya pusat data yang dapat menjadi rujukan informasi untuk lada putih Bangka.

Hal ini sangat disayangkan dikarenakan informasi tentang lada putih menjadi simpang siur dan tidak 


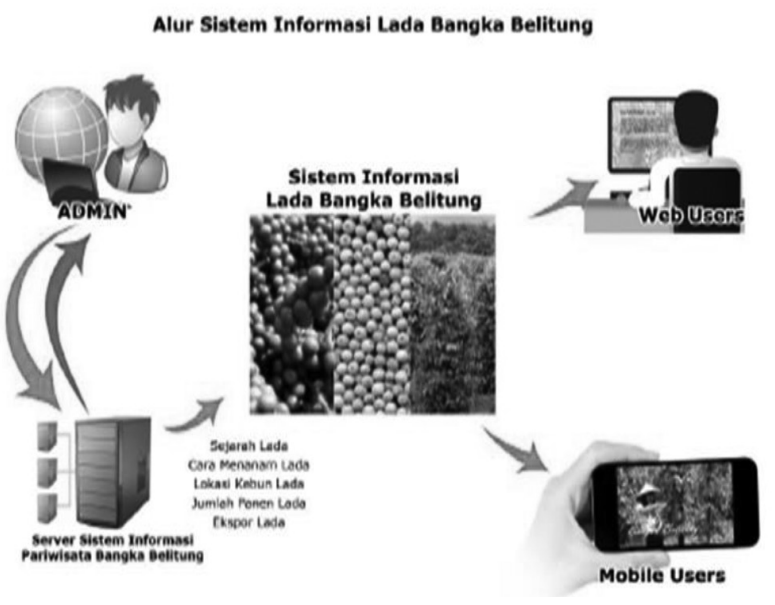

Gambar 2. Arsitektur sistem informasi lada

terpusat. Serta kebanyakan data tentang lada putih masih berbentuk kertas dan arsip sehingga akses informasi untuk lada putih ini menjadi terbatas dan hanya orang tertentu saja.

Dengan kemajuan teknologi informasi sudah seharusnya data data lada putih tersebut disimpan dalam bentuk digital untuk memudahkan akses informasi dengan menggunakan Internet serta penyimpanan data yang lebih aman. Karena itu, pada penelitian ini,akan merancang dan membangun sebuah sistempusat data digital dan spasial untuk lada putih di Bangka Belitung dengan nama e-lada, agar dapatmenjadi pusat informasi tentang lada putih dan menjadi rujukan bagi yang memerlukan informasi tentang lada putih Bangka.

Sistem ini akan dinamakan sistem e-lada dengan perancangan menggunakan model Software Development Life Cycle (SDLC) serta dibangun dengan bahasa pemrograman $\mathrm{PhP}$ dan MySQL sebagai pusat data digital dan spasial. Sistem ini juga akan berupa aplikasi mobile yang dapat diinstal di smartphone berbasis Android dengan nama aplikasi e-lada dan dibangun menggunakan Android Studio. Pusat data digital dan spasial ini diharapkan akan membantu banyak pihak mulai dari petani,

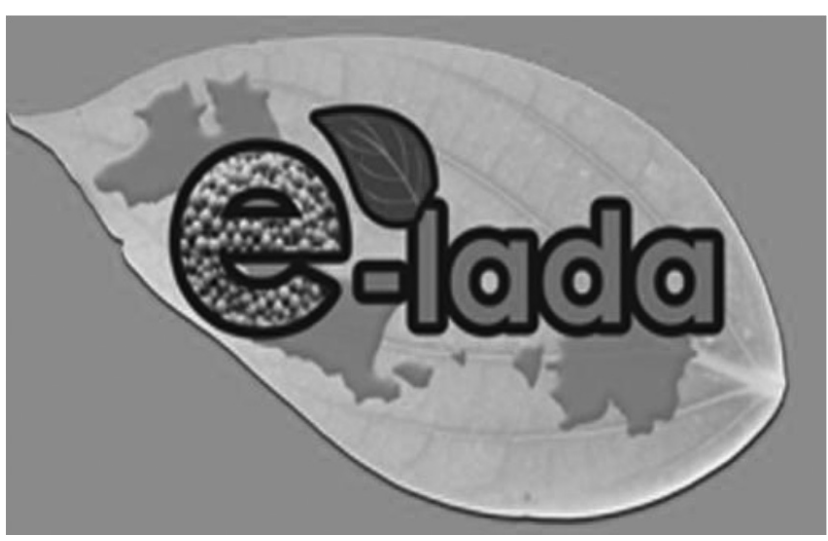

Gambar 3. Desain logo E-Lada

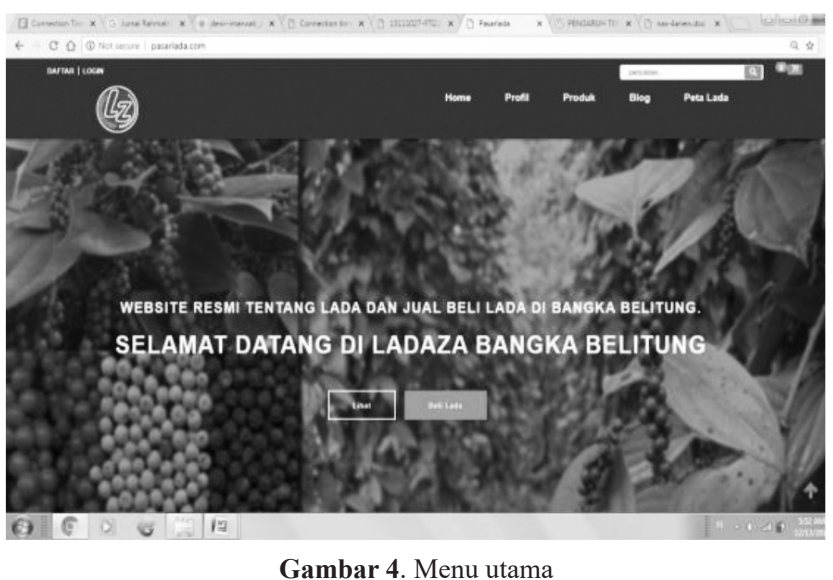

pemerintah, pedagang, masyarakat dan lain lain yang membutuhkan informasi tentang lada putih secara lengkap.

Tujuan penelitian ini adalah untuk menghasilkan pusat data digital dan spasial serta pemasaran online atau e-commerce untuk Lada putih dengan nama e-lada agar dapat membantu dalam pemasaran lada secara luas atau dengan kata lain petani dapat langsung menjual ladanya ke pembeli.

Pusat data ini akan terdiri dari data petani lada, data luas dan peta kebun lada di Bangka Belitung,data produksi lada,data stok lada, data harga lada,data pembeli, pemasaran lada dan lain lain yang dapat diakses menggunakan Internet dan aplikasi mobile.

\section{Tinjauan Pustaka}

\subsection{Nama, Tipe dan Sifat Khas Lada}

Tanaman Lada (pepper Ningrum L) merupakan tanaman yang tumbuh di daerah tropis pada daerah dengan ketinggian berkisar antara 50 sampai dengan 1500 meter dari permukaan laut. Selain itu tanaman lada dapat hidup dengan curah hujan rata-rata 2.000 - $3.000 \mathrm{~mm} /$ tahun dan musim kemarau hanya 2-3 bulan/ tahun.

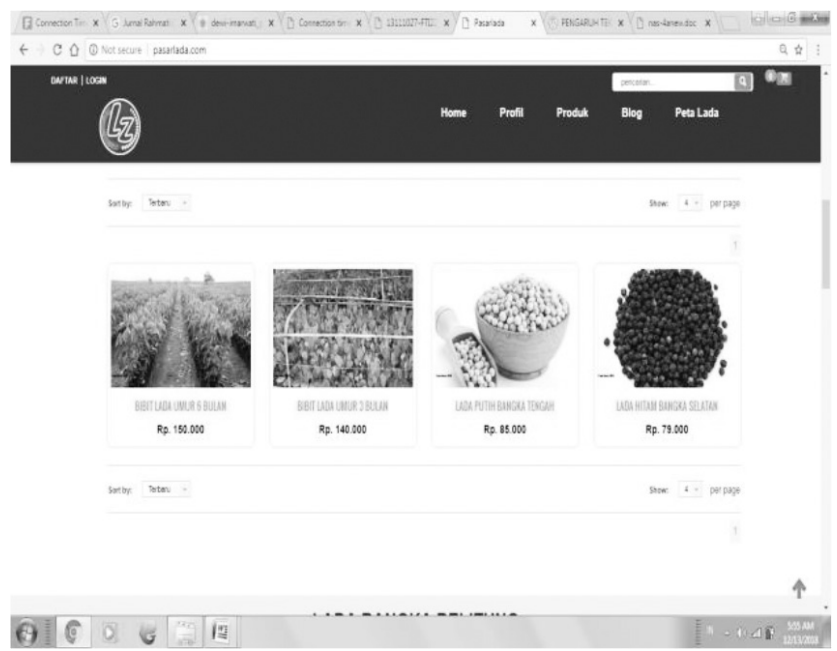

Gambar 5. Produk dan harga lada 

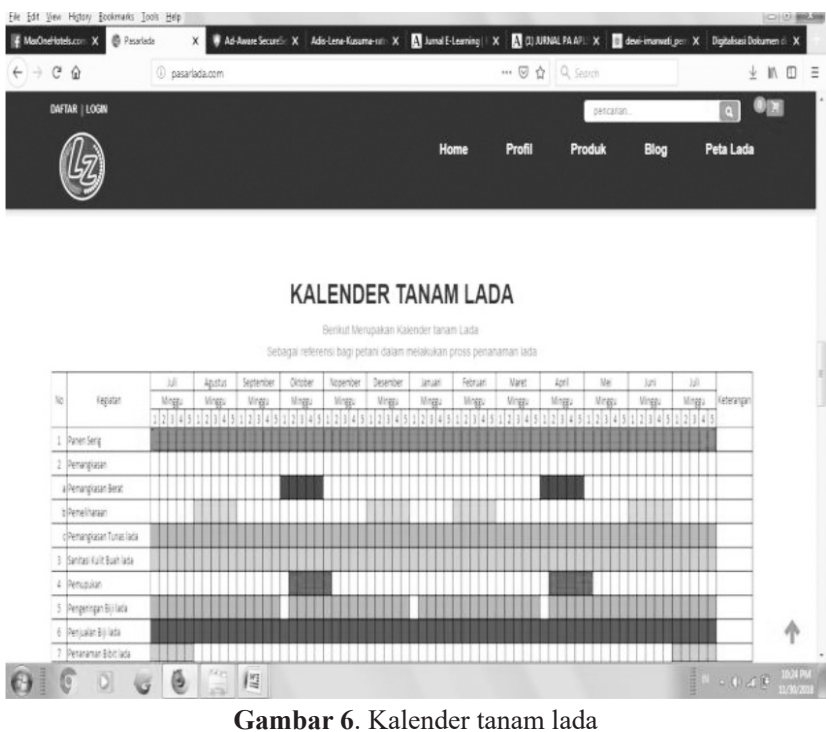

Salah satu jenis lada yang terkenal adalah lada putih dan diproduksi oleh Bangka belitung dengan nama branded Muntojk White Pepper yang dikenal sejak abad XIX oleh bangsa bangsa Eropa. Muntok yang dimaksud adalah nama kota tua yang berdiri sejak berabad abad yang silam. Dari kota tua ini, lada putih asal Bangka dikirim melalui pelabuhan Muntok sehingga menjadi trade mark Muntok white pepper.

\subsection{Digitalisasi}

Menurut istilah, digitalisasi adalah "Proses pemberian atau pemakaian sistem digital" (Kamus Besar Bahasa Indonesia). Sedangkan sistim digital itu sendiri adalah Susunan peralatan yang dirancang untuk mengolah besaran fisik yang diwakili oleh besaran digital. Digitalisasi informasi adalah proses mengubah berbagai informasi, kabar, atau berita dari format analog menjadi format digital sehingga lebih mudah untuk diproduksi, disimpan, dikelola dan didistribusikan.

\subsection{E-Commerce}

Electronic Commerce (e-commerce) adalah proses
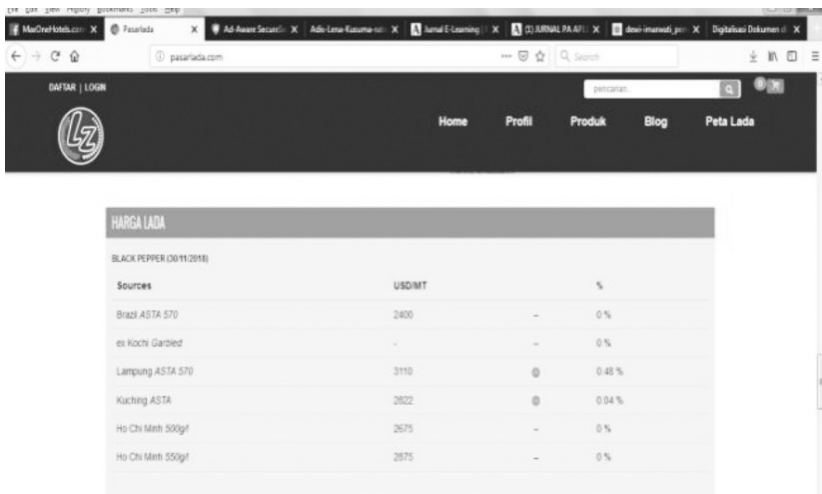

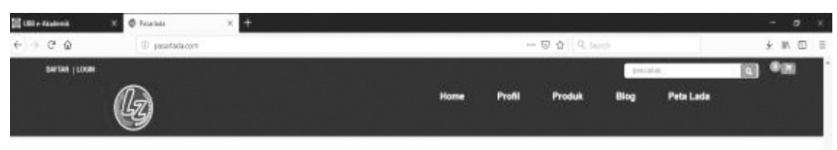

BERITA TERBARU
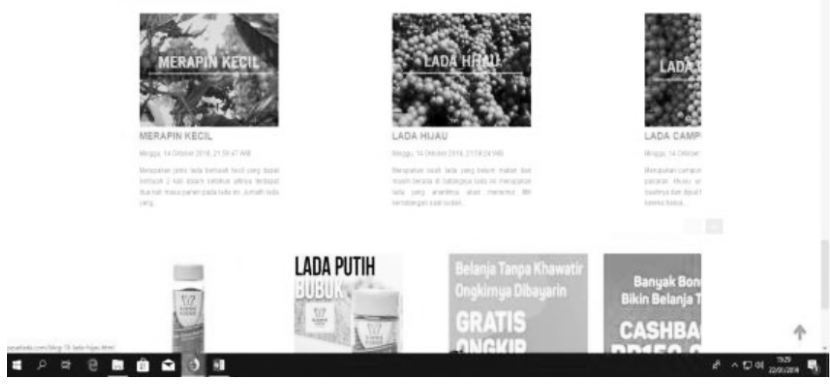

Gambar 8. Berita Lada

pembelian, penjualan atau pertukaran produk, jasa dan informasi melalui jaringan komputer. E- commerce merupakan bagian dari e-business, di mana cakupan e-business lebih luas, tidak hanya sekedar perniagaan tetapi mencakup juga pengkolaborasian mitra bisnis, pelayanan nasabah, lowongan pekerjaan dll.

Menurut Rahmati (2009) E-commerce singkatan dari Electronic Commerce yang artinya sistem pemasaran dengan media elektronik. E- Commerce ini mencakup distribusi, penjualan, pembelian, marketing dan service dari sebuah produk yang dilakukan dalam sebuah sistem elektronika seperti Internet atau bentuk jaringan komputer yang lain. E-commerce bukan sebuah jasa atau sebuah barang, tetapi merupakan perpaduan antara jasa dan barang.

\subsection{PHP (Hypertext Preprocessor)}

PHP adalah bahasa pemrograman script serverside yang didesain untuk pengembangan web. Selain itu, PHP juga dapat digunakan sebagai pemrograman umum. PHP dikembangkan pada tahun 1995 oleh Rasmus Ledorf dan sekarang

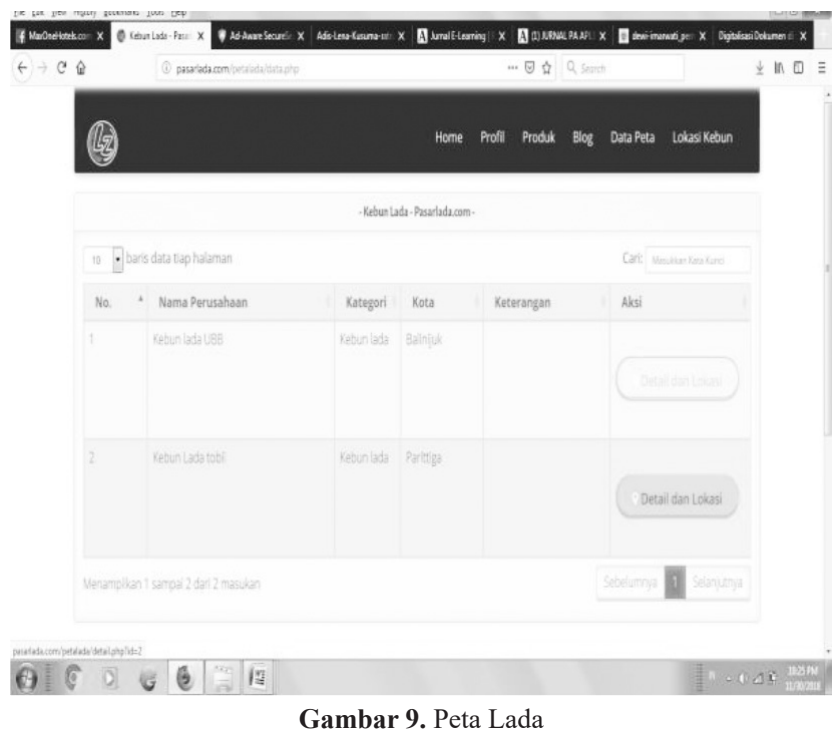




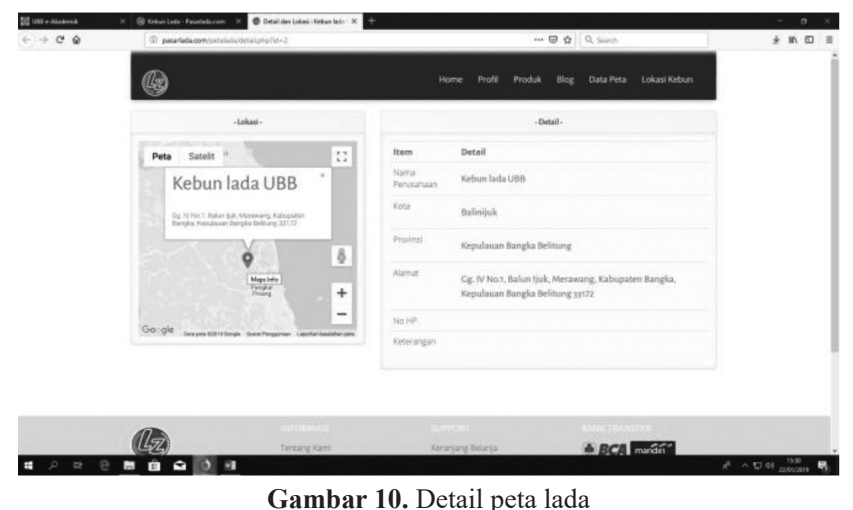

dikelola oleh the PHP Group dengan situs resmi beralamat http://www.php.net

\subsection{MySQL}

Menurut Kadir (2002) MySQL tergolong "sebagai DBMS (Database Management System) yang bermanfaat untuk mengelola datadengan cara yang sangat fleksibel dan cepat"

\section{Metode Penelitian}

\subsection{Alat dan Bahan Penelitian}

Alat dan bahan yang digunakan dalam penelitian ini adalah:

1. $P C$ (Server)

2. Laptop (Client)

3. HDD Eksternal $1 \mathrm{~TB}$

\subsection{Tahapan Penelitian}

Berikut fase pembangunan sistem digitalisasi data Muntok White Pepper dengan metode waterfall berbasis website dan aplikasi Android yang akan dikerjakan :

\section{Tahap Perencanaan}

a. Mendefinisikan dan mengumpulkan data yang berhubungan dengan lada Bangka

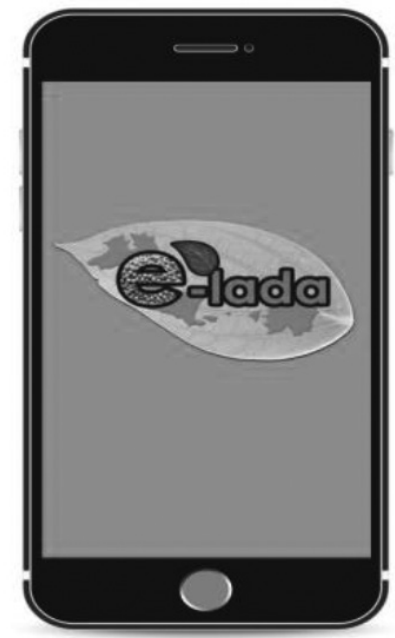

Gambar 11. Tampilan awal aplikasi android

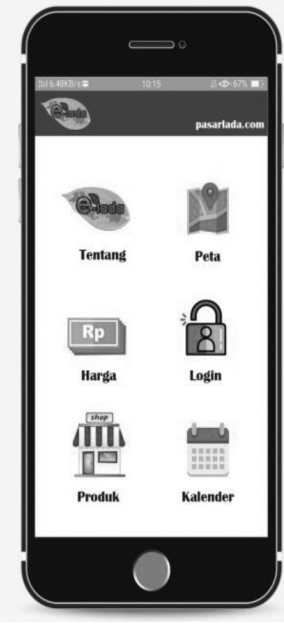

Gambar 12. Tampilan utama aplikasi android

b. Membuat jadwal pengambilan data

\section{Tahap Analisis}

a. Mengumpulkan informasi yang berhubungan dengan Muntok White Pepper serta persiapan melakukan digitalisasi data

b. Menganalisis kebutuhan yang diperlukan pada sistem, melakukan digitalisasi data Mutok White pepper dari kertas menjadi digital sehingga bisa diakses via Internet dan aplikasi Android.

\section{Tahap Perancangan Sistem Secara Umum}

a. Menyiapkan rancangan aplikasi yang berisikan data tentang lada, cara kerja sistem dan implementasinya

b. Merancang struktur database yang akan digunakan pada sistem digitalisasi di website dan aplikasi

\section{Tahap Perancangan Sistem Secara Detail}

a. Perancangan antarmuka sistem digitalisasi

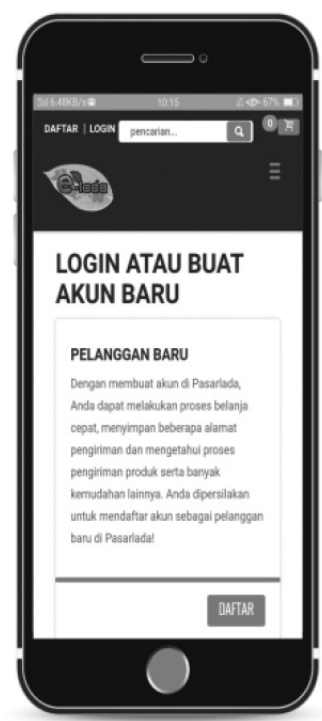

Gambar 13. Tampilan untuk login 


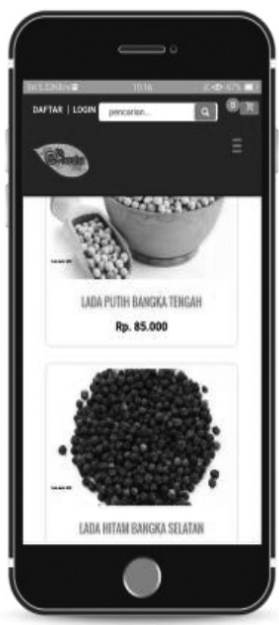

Gambar 14. Tampilan produk dan harga

baik website maupun aplikasi mobile

b. Desain aplikasi dan website.

c. Perancangan database untuk penyimpanan data digital dan mengakses

\section{Tahap Pembuatan Sistem}

a. Pembuatan aplikasi android dan website lada

b. Memasukkan data digitalisasi lada dari data lahan, kalender tanam, data harga dan lain lain yang berhubungan dengan lada

6. Tahap Implementasi

a. Memverifikasi dan percobaan sistem.

b. Membuat dokumentasi

c. Menginstal sistem

7. Tahap Pemeliharaan

a. Adanya permintaan modifikasi dan perubahan

b. Mengimplementasi perubahan

d. Mengembangkan sistem

\subsection{Perancangan Sistem}

\subsubsection{Gambaran Umum Sistem}

Saat ini, pemasaran lada masih dilakukan secara tradisional, dengan cara dari petani, ke pengepul baru

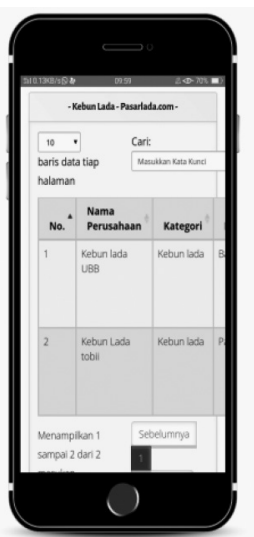

(a)

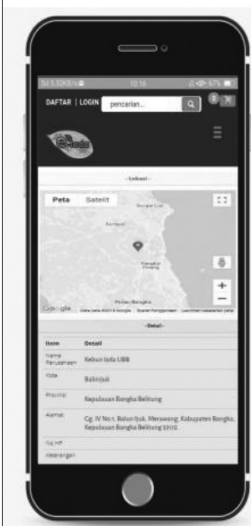

(b)
Gambar 15. (a) dan ( b). Menu untuk peta lada ke pedagang besar atau eksportir. Hal ini, membuat harga lada ditentukan oleh pedagang besar atau eksportir. Masih banyak petani belum menggunakan pemasaran secara online dikarenakan belum adanya sistem pemasaran online yang khusus untuk lada. Hal ini sangat disayangkan karena perkembangan teknologi informasi dan Internet yang demikian pesat, sudah seharusnya petani sudah menggunakan media Internet untuk menjual lada mereka.

Dengan sistem ini, pengolahan dan pemasaran lada lebih ke pemanfaatan Internet dan aplikasi android untuk mendapatkan informasi dan pengembangan untuk mendukung e-commerce khusus lada dikarenakan pemasaran lada yang masih sama sejak dahulu. Serta sistem ini diharapkan dapat menjadi sistem pemasaran digital atau berbasis Internet yang membutuhkan kerjasama dengan pihak petani dan pemerintah agar sistem pemasaran dapat digunakan dan menjadi pusat jual beli lada dengan tujuan agar harga lada lebih baik dibandingkan sebelumnya.

Sistem akan dibangun menggunakan $\mathrm{PhP}$ dan databse MySQL agar dapat diakses via Internet dengan menu yang lengkap untuk memudahkan petani dan pembeli mendapatkan informasi tentang lada.

Gambaran umum sistem dapat dilihat pada Gambar 2. dimana pada Gambar 2 menunjukkan bagaimana sistem ini dapat diakses menggunakan komputer dan smartphone berbasis android untuk memudahkan user baik petani maupun pembeli mendapatkan informasi yang dibutuhkan yang berhubungan dengan lada.

\section{Hasil Dan Pembahasan \\ 4.1. Analisa Sistem Digitalisasi}

Pusat data ini akan menjadi pusat informasi tentang lada putih yang dapat diakses via Internet dan mengubah data lada putih dari berbentuk kertas (hardcopy) menjadi softcopy atau data digital sehingga mudah untuk disimpan,dikelola dan di akses bagi yang membutuhkan. Pusat data digital dan spasial ini akan dirancang juga untuk dapat melakukan proses jual beli lada secara online atau e-commerce untuk memudahkan petani ketika menjual ladanya dan mendapatkan harga yang lebih baik.

1. Pusat data digital dan spasial ini mempunyai nama E-Lada sehingga mudah untuk diingat ketika melakukan akses dan menggunakan sis-tem ini.

2. Perancangan menggunakan Metode SDLC dengan menggunakan metode waterfall agar sistemini mudah untuk dibangun

3. Data yang ada akan diubah menjadi digital terlebih dahulu dan dibuat database lengkap untuk data lada putih yang telah menjadi data digital sehingga bisa diakses secara online 
4. E-lada juga mempunyai logo sebagai merek dagang untuk sistem pusat data.

5. Pusat data akan dibangun menggunakan baha-sa pemrograman PhP dan MySQL sebagai pengolahan database lada putih. Penggunaan PhP dan MySQL dengan tujuan pusat data ini dapat diakses via Internet dan akan ada administrator yang akan mengelola sistem ini

6. Merancang antar muka baik untuk website maupun untuk aplikasi mobile sehingga pusat data mudah digunakan dan dipahami ketika diakses dan digunakan.

7. Sistem ini juga akan mendukung e-commerce agar memudahkan dalam proses penjualan lada

8. Membangun aplikasi mobile menggunakan Android Studio agar dapat digunakan di smartphone berbasis Android. Hasil pene-lusuran via Google baik website maupun ap-likasi android di Google Play Store yang dil-akukan menunjukkan hasil bahwa belum ada pusat data informasi dan rujukan dalam hal in-formasi lada putih.

9. Karena itu dibutuhkan sebuah pusat data agar dapat membantu akses informasi tentang lada putih yang ada di Bangka Belitung agar mem-bantu pihak yang memerlukan data tersebut. Dengan data yang lengkap dan bisa diakses akan memudahkan dalam pengelolaan data dan memberikan informasi bagi yang membu-tuhkan.

\subsection{Tampilan Website Pusat Lada}

Pada bagian ini akan menjelaskan tampilan dan layanan yang diberikan di sistem digitalisasi lada yang telah dibangun dan dapat diakses di www. pasarlada.com untuk memudahkan petani dan pembeli berintaraksi dan mendapatkan informasi tentang lada. Pada Gambar 3, merupakan desain logo E-Lada sebagai logo dari sistem digitalisasi ini.

Pada Gambar 4. Dapat dilihat menu yang tersedia di www.pasarlada.com mulai dari Home untuk kembali ke halaman pertama, Profil yang berisikan profil pasarlada.com, Produk merupakan informasi yang berisikan produk produk yang disediakan, Blog merupakan berita berita yang berhubungan dengan lada serta Peta Lada yang menampilkan data perkebunan lada yang ada di Bangka.

Pada Gambar 4 ini untuk memudahkan user ketika menggunakan sistem ini, selain itu juga tersedia menu daftar untuk mendaftarkan diri menjadi pembeli produk yang disediakan oleh sistem ini.

Pada Gambar 5. Menampilkan informasi produk yang ada berupa gambar dan harga dari produk tersebut sehingga memudahkan pembeli untuk mendapatkan informasi.
Gambar 6 menampilkan kalender tanam lada untuk memudahan petani ketika ingin melakukan penamaman lada dengan tujuan mendapatkan hasil yang lebih maksimal.

Pada Gambar 7 menunjukkan harga lada dunia yang dikeluarkan oleh IPC untuk menjadi rujukan petani dan pembeli dalam penentuan harga jual lada. Data harga lada ini realtime sehingga begitu terjadi perubahan maka harga otomatis berubah mengikuti harga terbaru.

Pada Gambar 8 memberikan informasi yang berhubungan dengan lada untuk memudahkan mendapatkan informasi terbaru tentang lada.

Pada Gambar 9 menunjukkan data perkebunan lada yang ada di Bangka dan dapat dipilih untuk mellihat detail dan lokasi dengan menggunakan aplikasi google maps sehingga lokasi ditunjukan dalam bentuk peta.

Pada Gambar 10 menunjukkan data perkebunan lada dalm bentuk peta dan detail data kebun lada tersebut

\subsection{Rancangan Tampilan Untuk Aplikasi Android}

Pada bagian ini akan membahas desain aplikasi android yang akan digunakan untuk pusat data lada yang dapat diinstal di smartphone Android.

Pada Gambar 11, merupakan tampilan awal aplikasi android sehingga mudah untuk diingat.

Pada Gambar 12, merupakan tampilan manu yang ada di aplikasi android yang berisikan harga, login, peta, produk dan lain lain yang berhubungan dengan lada.

Pada Gambar 13, merupakan tampilan untuk proses Login bagi pembeli agar data pembeli tersimpan dalam databse sistem dan memudahkan proses jual beli mengunakan aplikasi ini.

Pada Gambar 14. merupakan tampilan untuk informasi harga dan detail produk yang ditawarkan sehingga pembeli mendapatkan infromasi tentang produk yang akan dibeli.

Gambar 15 menunjukkan informasi dan lokasi perkebunan lada yang ada di bangka sehingga memudahkan dalam mendapatkan informasi luas dan lokasi perkebunan lada.

\section{Kesimpulan}

Saat ini belum ada pusat data digital dan spasial untuk lada putih yang dapat diakses via Internet yang dapat menjadi rujukan bagi petani dan masyarakat untuk memperoleh informasi tentang lada. Pemanfaatan teknologi Informasi terutama Internet dan Android untuk pengolahan dan akses data lada putih Bangka agar dapat menjadi sebuah pusat informasi dan rujukan bagi yang membutuh-kan data lada putih yang ada di Bangka dan Belitung.

Sistem digitalisasi ini akan dibangun menggunakan 
PhP, MySQL dan Android Studio sehingga dapat diakses dengan situs pasarlada.com via Internet dan dapat di install di smartphone berbasis android dengan nama E-Lada sebagai nama untuk sistem dan pusat data digital dan spasial untuk lada putih. E-Lada akan mempunyai data petani lada putih di Bangka Belitung, peta dan luas perkebunan lada yang ada di Bangka Belitung serta data produksi lada dari tiap kebun lada yang ada. Sistem ke depan diharapkan dapat membantu petani dalam menjual lada mereka dan mendapatkan harga yang lebih baik.

\section{Ucapan Terima Kasih}

Peneliti mengucapkan terima kasih kepada Kementerian Riset dan Pendidikan Tinggi Indonesia atas bantuan dana penelitian di skema Penelitian Dosen Pemula sehingga penelitian ini bisa dilakukan.

\section{Daftar Pustaka}

Allen, G. 2012. Beginning Android 4. Penerbit A Press. New York

Badan Pengelolaan, Pengembangan dan Pemasaran Lada (BP3L) Bangka Belitung, 2009. Buku Persyaratan Indikasi Geografis. Pangkalpinang BP3L
BPS Provinsi Kepulauan Bangka Belitung. 2017. Produksi Lada Bangka Belitung 2001-2015. www.babel.bps.go.id, diakses 4 Agustus 2018

Ginting, Kristiawan Hadinata. 2017. Analisis faktor faktor yang mempengaruhi produksi lada putih di Bangka Belitung. http://repository.ipb.ac.id/ handle/123456789/60257 diakses 10 Juli 2018 International Pepper Community (IPC). 2014. Pengendalian Penyakit dan Hama Tanaman Lada di Indonesia. Jakarta : IPC. www.ipc.net, diakses 01 Juli 2018

Kasiman Peranginangin, Aplikasi Web dengan PhP dan MySQL, Andi Publisher, 2006

Rahmati. 2009. Pemanfaatan E- Commerce dalam bisnis di Indonesia.

http://citozcome.blogspot.com/2009/05/ pemanfaatan-e commerce-dalam-bisnis.html, diakses 20 September 2018

http://developer.android.com/studip/intro/index.html, diakses 8 Agustus 2018

http://id.wikipedia.org/wiki/Digitalisasi informasi\#Digitalisasi_Informasi_di_ Indonesia, diakses 01 Juli 2018

www.php.net diakses 2 Juli 2018 